\title{
Annellosporium nemorosum gen. et sp. nov., an annellidic anamorph with phylogenetic affinities to the genus Daldinia (Xylariales)
}

\author{
MARIE L. DAVEY
}

\begin{abstract}
DAVEY, M.L. 2010: Annellosporium nemorosum gen. et sp. nov., an annellidic anamorph with phylogenetic affinities to the genus Daldinia (Xylariales). - Karstenia 50: 1-10. Helsinki. ISSN 0453-3402.

During a survey of fungi occurring in soil from swift fox dens in a zoo enclosure in Alberta, Canada, a free-living xylariaceous mitosporic fungus was repeatedly isolated and is herein described as Annellosporium nemorosum gen. et sp. nov. The fungus is characterized by mononematous, dichotomously branched conidiophores with termini bearing groups of 1-3 cylindric, smooth to minutely roughened, enteroblastic, percurrently proliferating, annellated conidiogenous cells that produce sub-globose to obovate conidia with attenuated, flattened basal ends. Phylogenetic analysis of the $\beta$-tubulin region indicates $A$. nemorosum has strong phylogenetic affinities to the teleomorphic genus Daldinia (Xylariaceae, Xylariales), and is included in a clade with those Daldinia species known to produce Nodulisporium-like anamorphs with enteroblastic conidiogenesis, rather than the holoblastic conidiogenesis typical of true Nodulisporium species. A teleomorphic state was not observed, but is expected to be Daldinia loculata-like, given the close affiliation between this species and $A$. nemorosum that was revealed by phylogenetic analyses of the internal transcribed spacer (ITS) region of rDNA.
\end{abstract}

Key words: Daldinia, conidiogenesis, pleomorphism, Nodulisporium, Xylariaceae

Marie L. Davey, Department of Biological Sciences, University of Alberta, Edmonton, Alberta, Canada T6G $2 E 9$.

Present addresses: Department of Ecology and Natural Resource Management, Norwegian University of Life Sciences, P.O. Box 5003, N-1432 As, Norway; Microbial Evolution Research Group, Department of Biology, University of Oslo, PO Box 1066 Blindern, N-0316 Oslo, Norway; e-mail: marie.davey@umb.no

\section{Introduction}

The family Xylariaceae (Xylariales, Sordariomycetes) includes saprobes, plant endophytes, and pathogens, and is distinguished by the production of teleomorphic states that have perithecia-bearing stromata, and anamorphic states with blastic conidiogenesis from sympodially- or, more infrequently, percurrently- proliferating conidiogenous cells (Zhang et al. 2006, Tang et al. 2009). Daldinia is a genus of some 30 species within the Xylariaceae that produces obovoid to tubular perithecia within stipitate or sessile stromata (Ju et al. 1997). The genus is characterized by the production of stromata with concentric zones, asci with flattened, amyloid apical rings, darkly pigmented ascospores with a longitudinal germ slit, and Nodulisporium or Nodulisporiumlike anamorphs (Ju et al. 1997)

Anamorphic states associated with the genus Daldinia are described as being free-living on woody substrates or occurring on the surface of young teleomorphic stromata, and are referable to Nodulisporium (Ju et al. 1997). More specifically, the anamorphs exhibit a Nodulisporiumlike conidiophore branching pattern (sensu Ju \& Rogers 1996) whereby successive dichotomous or trichotomous branching of the conidiophores gives rise to multiple levels of terminal branches, all bearing 1-3 (rarely more) conidiogenous 
cells. In their revision of the genus Daldinia, Ju et al. (1997) describe anamorphic conidiogenesis as being holoblastic, with conidia being produced in sympodial sequence, as is typical for Nodulisporium. They note that $D$. petriniae Y.M. Ju, J.D. Rogers \& F. San Martin is an anomaly, exhibiting the typical Nodulisporium-like conidiophore branching pattern, but undergoing enteroblastic conidiogenesis from percurrently proliferating annellides. However the recent description of additional Daldinia species with annellidic anamorphs (D. barkalovii Lar. N. Vassiljeva \& M. Stadler, D. decipiens Wollw. \& M. Stadler, $D$. govorovae Lar. N. Vassiljeva \& M. Stadler, $D$. palmensis M. Stadler, Wollw. \& Tichy, D. singularis Y.M. Ju, Lar.N. Vassiljeva, \& J.D. Rogers) (Ju et al. 1999; Stadler et al. 2001, 2004; Vasileyeva \& Stadler 2008) suggests that this is a more common character within the group than previously thought. Furthermore, phylogenetic analyses of the $\beta$-tubulin and $\alpha$-actin genes suggest that mode of conidiogenesis is phylogenetically meaningful in this group, as those Daldinia species producing anamorphs with percurrently proliferating conidiogeneous cells form a monophyletic group within the genus Daldinia (Hsieh et al. 2005).

During a survey of fungi present in the soil of swift fox (Vulpes velox Say) dens in a zoo enclosure, an anamorphic xylariaceous fungus with enteroblastic conidiogenesis from percurrently proliferating annellides was repeatedly isolated and is herein characterized and described as $\mathrm{An}$ nellosporium nemorosum gen. et sp. nov.

\section{Materials and methods}

\section{Isolation and characterization}

Soil samples were collected from the entrance of swift fox dens at the Valley Zoo in Edmonton, Alberta, Canada, and used to make Warcup isolation plates (Warcup 1950). Within 30 days, A. nemorosum emerged and began to sporulate, at which time it was sub-cultured onto oatmeal agar (OA: $20 \mathrm{~g} \mathrm{l}^{-1}$ agar (Invitrogen, Carlsbad, CA), $20 \mathrm{~g} \mathrm{l}^{-1}$ ground oatmeal).

The microscopic morphology of the fungus was examined in 15-30 day old colonies on OA because this medium readily induces sporulation. Squash mounts of reproductive and sterile structures and mounts of 20-dold slide-cultures grown on cereal agar (CA: $100 \mathrm{~g} \mathrm{l}^{-1}$ Pablum, $20 \mathrm{~g} \mathrm{l}^{-1}$ agar) were made in lacto-fuchsin $(0.1 \mathrm{~g}$ acid fuchsin in $100 \mathrm{ml}$ lactic acid) or polyvinyl alcohol with acid fuchsin $(0.05 \mathrm{~g}$ acid fuchsin in $10 \mathrm{ml}$ lactic acid and $1 \mathrm{ml}$ glycerine mixed with $1.66 \mathrm{~g}$ polyvinyl alcohol dissolved in $10 \mathrm{ml}$ water) and light micrographs (LM) were taken using an Olympus BX50 microscope with a DP-12 digital camera. Measurements of important morphological features were made and are expressed as: range (mean \pm standard deviation). Samples were examined by cryo-scanning electron microscopy (C-SEM) using a Zeiss EVO MA 15 scanning electron microscope with a LaB6 crystal source and an Emitek 1250 cryogenic system. Samples were frozen by plunging into a liquid nitrogen slush, surface ice was removed by sublimation, the samples were sputter-coated with gold, and then examined at $5 \mathrm{kV}$.

\section{Phylogenetic analyses}

Fungal isolates were grown on PDA overlaid with a Cellophane ${ }^{\mathrm{TM}}$ membrane (UCB Films, Somerset, UK) for 30 $\mathrm{d}$ at ambient light and temperature. Genomic DNA was extracted using a CTAB extraction buffer, as described by Davey and Currah (2007) and purified using a QIAQuick PCR Purification kit (Qiagen, Mississauga, ON, Canada). The ITS region of the genomic rRNA gene complex was amplified as described in Davey \& Currah (2007) using the forward and reverse primer set ITS 5 (White et al. 1990) and LR1 (Vilgalys \& Hester 1990). The $\beta$-tubulin region of the genomic DNA was amplified with the forward and reverse primer set T1 and T22 (O'Donnell \& Cigelnik 1997) using illustra PuReTaq Ready-To-Go PCR BEADS (GE Healthcare, Piscataway, NJ, USA ) according to the manufacturer's instructions. Amplicons were sequenced with an ABI 3100 automated sequencer (Applied Biosystems Inc., Foster City, CA, USA) and the primers ITS5 (White et al. 1990) and LR1 (Vilgalys \& Hester 1990), and T1, T2, T12, T10, T22, and T121 (O’Donnell \& Cigelnik 1997).

Data matrices were assembled from ITS and $\beta$-tubulin sequences of Annellosporium nemorosum and other members of Daldinia, as well as outgroup taxa from the genus Hypoxylon, aligned using MAFFT version 6.717 (Katoh \& Toh 2008), and the subsequent alignments were manually verified. Ambiguously aligned bases were then removed using Gblocks version 0.91b (Castresana 2000) and the resulting matrices subjected to maximum parsimony, maximum likelihood, and Bayesian analyses. Maximum parsimony analyses were conducted using PAUP version 4.0d106 (Swofford 2003) with Fitch parsimony, random simple step-wise addition of taxa, tree bisection-reconnection (TBR) branch swapping, and gaps treated as missing data. Support for branching topologies was evaluated using 1000 resamplings of the data by bootstrapping analysis using the same criterion described above (Felsenstein 1985). All trees were scored for length in steps, consistency index $(\mathrm{CI})$, retention index $(\mathrm{RI})$, and homoplasy index (HI). The Bayesian information criterion in jModelTest v0.1.1 (Guindon \& Gascuel 2003, Posada 2008) was used to determine the best-fit model of evolution for both maximum likelihood and Bayesian analyses. Maximum likelihood analyses to determine the most likely tree and maximum likelihood bootstrap support for each dataset were conducted using GARLI version 1.0 (Zwick1 2006) with the selected models of evolution implemented. Bayesian analyses were conducted using MrBayes version 3.1 (Ronquist \& Huelsenbeck 
2003) with two independent runs of four Markov Chain Monte Carlo chains with $1.0 \times 10^{7}$ generations each, sampling trees every $1000^{\text {th }}$ generation. A final standard deviation $<0.01$ for the split frequency was taken as an indication that convergence had been achieved. The first $10 \%$ of sampled trees were discarded as burn-in and posterior probabilities for each node of the $50 \%$ majority rule consensus tree were recorded.

Annellosporium M.L. Davey gen. nov. MycoBank no.: MB518232

Etymology: Annello refers to the characteristic annellidic conidiogenous cells that differentiate this genus from Nodulisporium.

Ad Nodulisporium Preuss, sed cellularum conidiogenosarum cylindricae vel proliferations percurrentes ad conidia obovata ad subglobosa, truncata ad extremum proximum. Typus Generis: Annellosporium nemorosum M.L. Davey

Conidiophores mononematous, dichotomously to trichotomously branched, hyaline, with 1-3 conidiogenous cells arising from each terminus. Conidiogenous cells terminal or intercalary, cylindrical, smooth to minutely roughened, percurrently proliferating, with apical annellations. Conidia ellipsoid to sub-globose with tapered to truncate basal ends.

\section{Annellosporium nemorosum M.L. Davey - Figs 1, 2 \\ MycoBank no.: MB518233}

Etymology: Nemorosum refers to the microscopic appearance of sporulating cultures and the conidiophore branching pattern, which gives the conidiogenous apparatus a tree-like form.

Conidiophora ad Nodulisporium Preuss. Cellularum conidiogenosarum cylindricae, levis, vel proliferations percurrentes. Conidia hyalina, levia, obovata ad subglobosa, truncata ad extremum proximum.

Colonies on OA white to pale grey, felty, azonate, with tan areas of sporulation after 20-30 days, developing dark brown patches with age. Vegetative hyphae hyaline, 1-2 $\mu \mathrm{m}$ diam. Bramble-like aggregates of irregularly branched, reticulated, thick walled, darkly pigmented sterile hyphae develop with age (Figs. 1A, 2A, 2B). Conidi- ophores mononematous, arising from vegetative hyphae, dichotomously (occasionally trichotomously) branched (Figs. 1C, 2C), hyaline 3-4 $\mu \mathrm{m}$ diam, with 1-3 conidiogenous cells arising from each terminus (Figs. 1C, 2D, 2E). Conidiogenesis enteroblastic, occurring on cylindrical, smooth to minutely roughened, percurrently proliferating, conidiogenous cells, (7-)10-16(-19) $(13 \pm 2.9) \times 2.5-4(3 \pm 0.4) \mu \mathrm{m}$, with successively tapered apical annellations, each up to $1 \mu \mathrm{m}$ in height (Figs. 1C, 2F, 2G). Conidia short ellipsoid to obovate, occasionally sub-globose, $2.5-4$ $(3.1 \pm 0.4) \times 4.5-7(6.1 \pm 0.8) \mu \mathrm{m}$, tapering slightly to a truncate basal end (Figs. 1B, 2G, 2H).

Typus: Canada, Alberta: prepared slides of conidiogenous structures of strain Sf-1 isolated from soil from Vulpes velox burrows in a zoo enclosure. (UAMH 11227 - Holotypus).

\section{Phylogenetic analyses}

The aligned matrix of $\beta$-tubulin sequences included 1488 characters, of which 1016 were constant, 179 were parsimony uninformative, and 293 were parsimony informative. Two most parsimonious trees of 960 steps $(\mathrm{CI}=0.654$, $\mathrm{RI}=0.601, \mathrm{HI}=0.346$ ) were generated by maximum parsimony analysis. The HKY + I model was selected by jModelTest as the best-fit model of evolution for the data and was implemented in both maximum likelihood and Bayesian inference analyses. Results of the maximum parsimony and maximum likelihood bootstrap analyses, and the Bayesian inference are shown on the maximum likelihood tree (- $\operatorname{lnL} 6567.30)$ (Fig. 2). Both parsimony and likelihood analyses yielded congruent tree topologies that group $A n$ nellosporium nemorosum with D. loculata (Lev.) Sacc. in a strongly supported clade (98\% maximum likelihood bootstrap proportion [BP]/99\% maximum parsimony bootstrap proportion $[\mathrm{PBP}] / 100 \%$ Bayesian posterior probability [BPP]). The A nemorosum- $D$. loculata clade is moderately supported $(80 \% \mathrm{BP} / 68 \% \mathrm{PBP} / 99 \%$ $\mathrm{BPP})$ as sister to a strongly supported clade (95\%BP/87\% PBP/100\% BPP) of other Daldinia species producing anamorphs with percurrently proliferating conidiogenous cells. This clade is nested within a strongly supported $(96 \% \mathrm{BP} / 100 \% \mathrm{PBP} / 100 \% \mathrm{BPP})$ sub-clade of the teleomorph genus Daldinia that also includes 
species with holoblastic conidiogenesis from sympodially proliferating conidiogenous cells.

The aligned matrix of ITS rDNA sequences included 510 characters, of which 356 were constant, 46 were parsimony uninformative, and 98 were parsimony informative. Maximum parsimony analysis generated 30 most parsimonious trees, each with 257 steps $(\mathrm{CI}=0.712, \mathrm{RI}=0.914$, $\mathrm{HI}=0.288)$. jModelTest identified the TrNef + $\mathrm{G}$ model as the best-fit model of evolution for the data, and maximum likelihood analysis of the dataset under these model parameters generated a maximum likelihood tree with likelihood $-\operatorname{lnL} 1998.28$ on which results of the maximum parsimony and maximum likelihood bootstrap analyses, and the Bayesian inference are shown (Fig. 3). Both parsimony and likelihood analyses were congruent with their placement of $A$. nemorosum within a well supported clade $(88 \% \mathrm{BP} / 92 \% \mathrm{PBP} / 96 \% \mathrm{BPP})$ comprised of representatives of the teleomorphic species Daldinia loculata. The A. nemorosum-D. loculata clade is well resolved from all other species of Daldinia with holoblastic sympodial conidio- genesis or with percurrently proliferating conidiogenous cells. However, the position of the $A$. nemorosum- $D$. loculata clade among these species remains unresolved in the ITS analysis.

\section{Discussion}

Annellosporium nemorosum morphologically most closely resembles those anamorphic states of Daldinia with percurrently proliferating conidiogenous cells, and shares their Nodulisporium-like conidiophore branching pattern, smooth to minutely roughened annellides, and obovate conidia with attenuated, flattened bases. However, A. nemorosum is distinguished from most of these anamorphs by its small conidia (4.5-7 $\times 2.5-4 \mu \mathrm{m})$. While several other Daldinia species also produce anamorphs with conidia of a similar size (D. caldariorum Henn., D. clavata Henn., D. eschscholzii (Ehrenb.) Rehm, D. mexicana F. San Martin, Y.M. Ju \& J.D. Rogers) (Ju et al. 1997), these are readily distinguished from A. nemorosum on the basis of mode of conidiogenesis and conidium shape. Only $D$. singularis

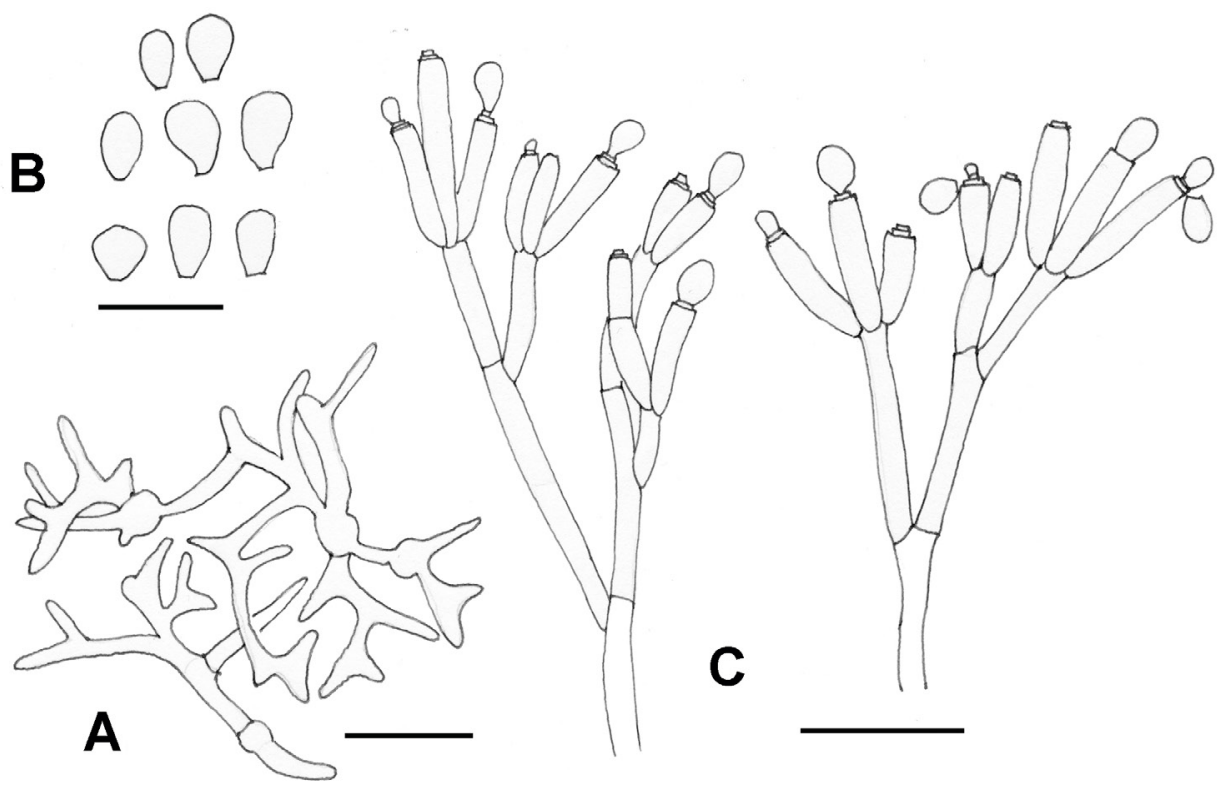

Fig, 1. Line drawings of Annellosporium nemorosum. A = bramble-like aggregate of irregularly branched, thick walled, sterile hyphae. Scale bar $=20 \mu \mathrm{m}, \mathrm{B}=$ sub-globose to obovate conidia with attenuated, truncate, flattened basal ends. Scale bar $=10 \mu \mathrm{m}, \mathrm{C}=$ mononematous conidiophores with branches terminating in annellidic conidiogenous cells. Scale bar $=20 \mu \mathrm{m}$. 


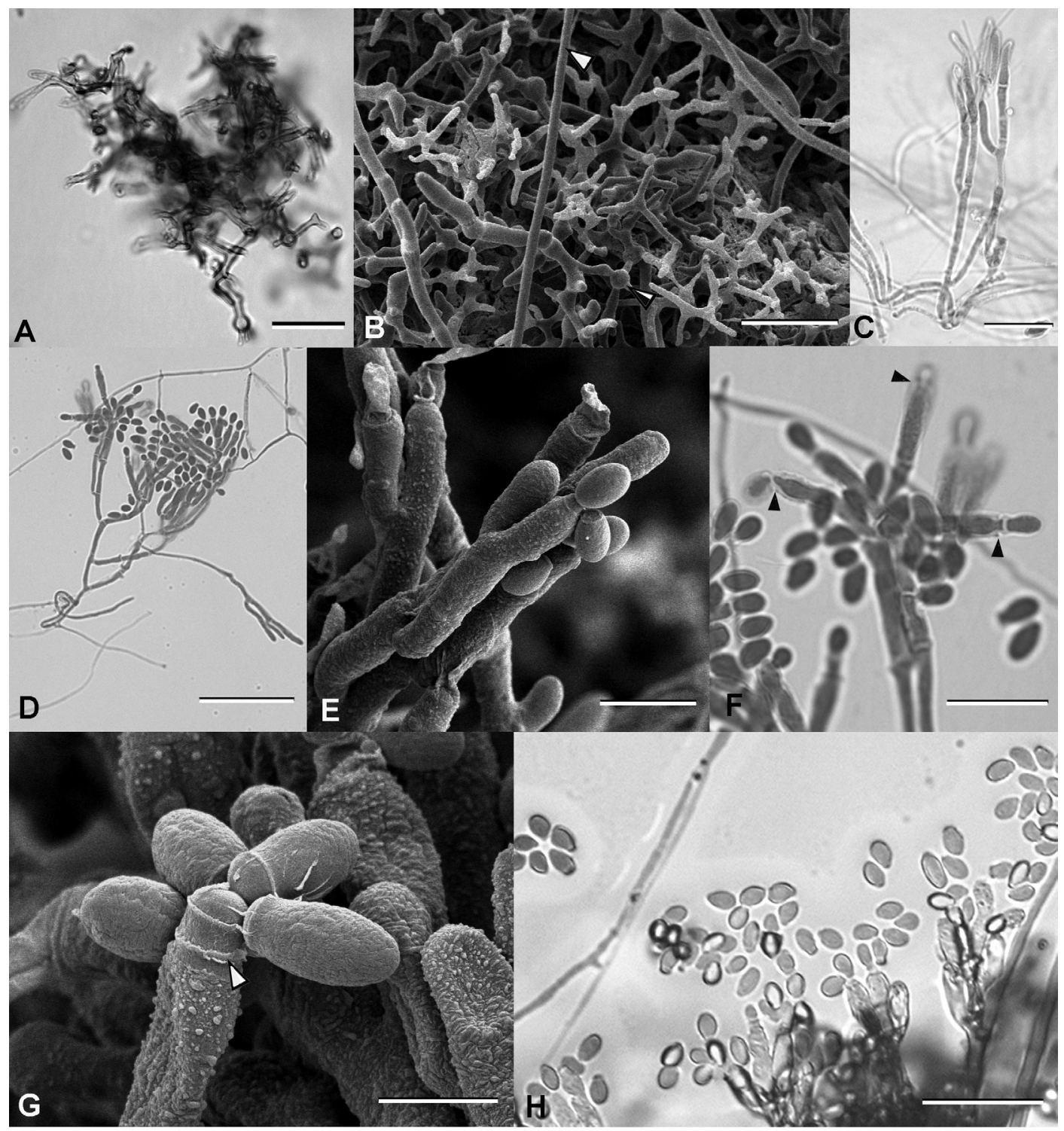

Fig. 2. Microscopic morphology of Annellosporium nemorosum. (A, C, D, F, H = light micrographs, B, E, G = cryoscanning electron micrographs). $\mathrm{A}=$ bramble-like aggregate of irregularly branched, reticulated, thick walled, darkly pigmented sterile hyphae. Scale bar $=12 \mu \mathrm{m}, \mathrm{B}=$ vegetative hyphae (white arrowhead) and bramble-like aggregate of reticulated, sterile hyphae with swollen nodes (bi-coloured arrowhead). Scale bar $=15 \mu \mathrm{m}, \mathrm{C}=$ immature conidiophore with multiple septations and repeated dichotomous branching. Scale bar $=15 \mu \mathrm{m}, \mathrm{D}=$ mature conidiogenous apparatus with branches terminating in 1-3 percurrently proliferating conidiogenous cells. Scale bar $=35 \mu \mathrm{m}, \mathrm{E}=$ apical portion of conidiogenous apparatus with asynchronously developing, enteroblastic conidiogenous cells. Scale bar $=10$ $\mu \mathrm{m}, \mathrm{F}=$ enteroblastic conidiogenous cells with apical annellations (arrowheads). Scale bar $=16 \mu \mathrm{m}, \mathrm{G}=$ percurrently proliferating conidiogenous cell with pronounced apical annellations (arrowhead) and roughened surface. Scale bar $=$ $5 \mu \mathrm{m}, \mathrm{H}=$ sub-globose to obovate conidia with attenuated, truncate basal end. Scale bar $=20 \mu \mathrm{m}$. Photos M.L. Davey 


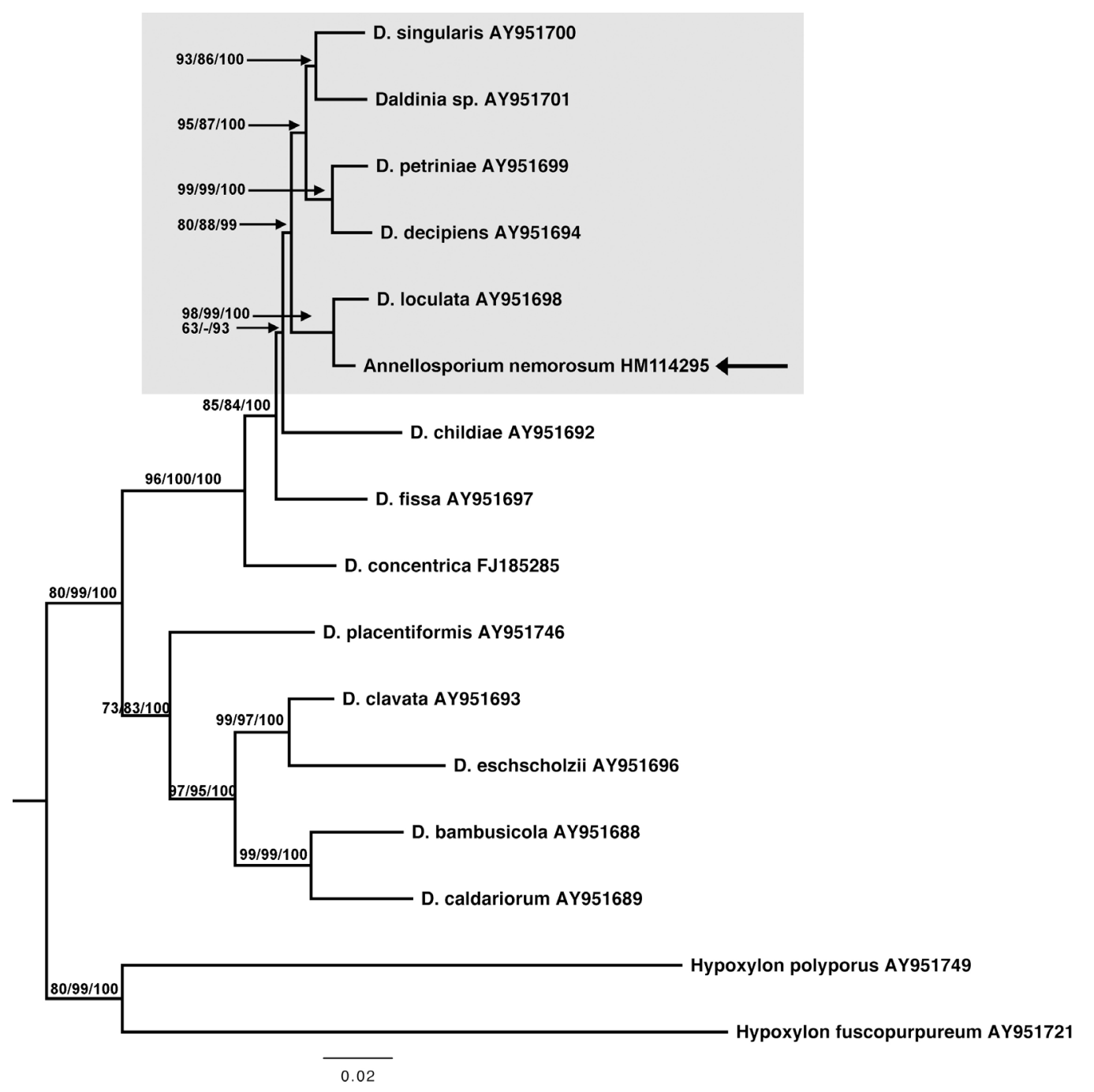

Fig. 3. Maximum likelihood tree (- $\operatorname{lnL} 6567.30)$ inferred from analysis of $\beta$-tubulin sequences showing the placement of Annellosporium nemorosum (arrow) among members of Daldinia. Hypoxylon polyporus and Hypoxylon fuscopurpureum serve as outgroup taxa. The shaded area indicates those species exhibiting enteroblastic conidiogenesis. Bootstrap values greater than $50 \%$ calculated from 1000 replicates and Bayesian posterior probabilities greater than 50 are given above the branches as maximum likelihood bootstrap proportion/maximum parsimony bootstrap proportion/ Bayesian posterior probability. Gaps (-) indicate a collapsed node in an analysis. GenBank accession numbers are given following species names. 


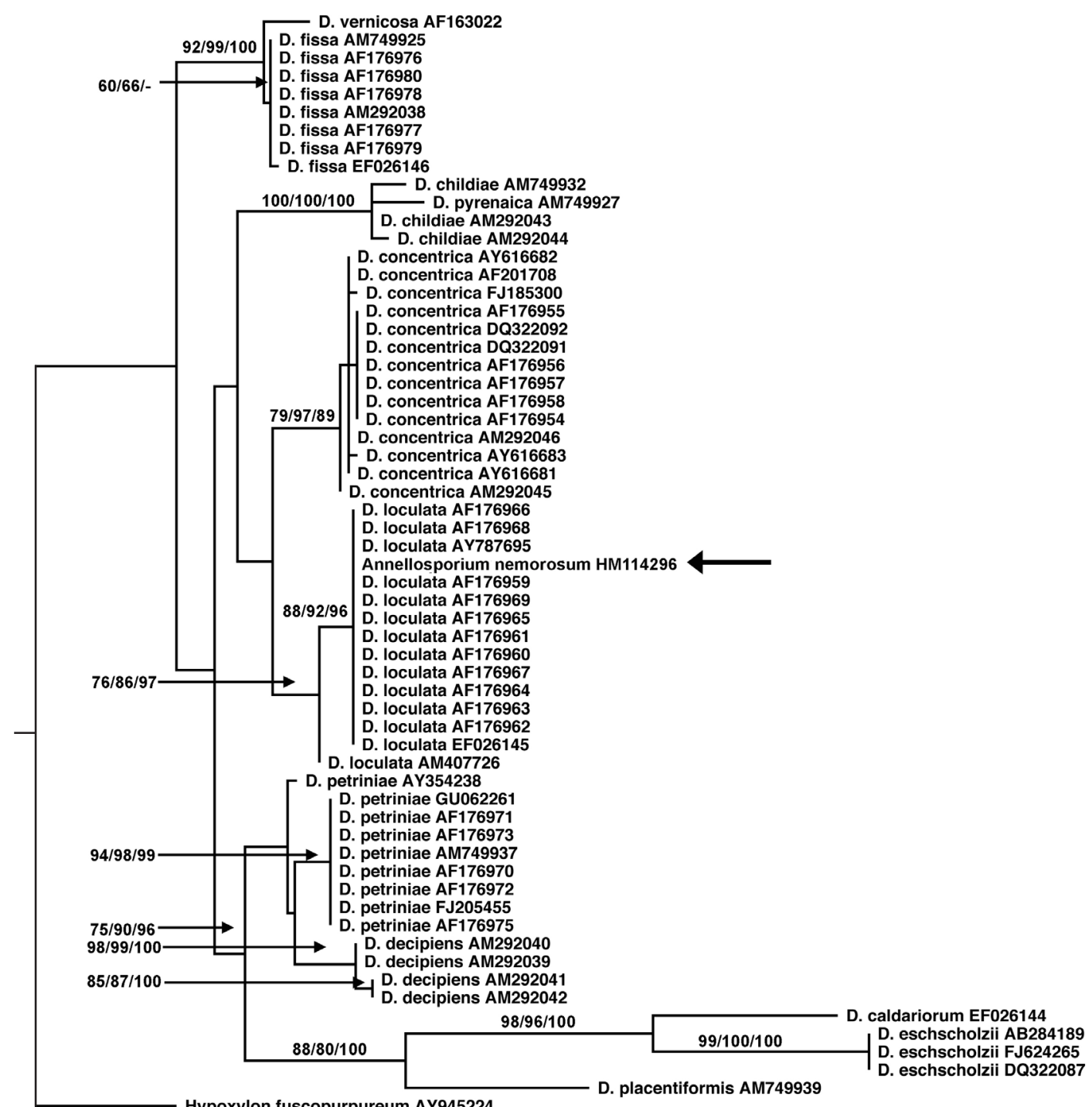

Hypoxylon fuscopurpureum AY945224

0.03

Fig. 4. Maximum likelihood tree (- $\operatorname{lnL} 1998.28)$ inferred from analysis of ITS sequences showing the placement of Annellosporium nemorosum (arrow) among members of Daldinia. Hypoxylon fuscopurpureum serves as the outgroup taxon. Bootstrap values greater than 50\% calculated from 1000 replicates and Bayesian posterior probabilities greater than 50 are given above the branches as maximum likelihood bootstrap proportion/maximum parsimony bootstrap proportion/Bayesian posterior probability. Gaps (-) indicate a collapsed node in an analysis. GenBank accession numbers are given following species names. 
produces an anamorph with conidia of a similar size via enteroblastic conidiogenesis from percurrently proliferating conidiogenous cells. However, this anamorphic state differs from $A$. nemorosum in its twisted conidiophores that terminate in a single conidiogenous cell (Ju et al. 1999), rather than straight conidiophores terminating in 1-3 conidiogenous cells.

Anamorph type is known to be phylogenetically meaningful in the Xylariaceae, with those genera producing Geniculosporium-like, Libertella-like, and Xylocladium-like anamorphs each forming single clades in multigene analyses, and those genera producing Nodulisporium-like anamorphs forming two monophyletic lineages (Triebel et al. 2005, Tang et al. 2009). The mitosporic species A. nemorosum is a Nodulisporium-like anamorph sensu Ju \& Rogers (1996) and has phylogenetic affinities to the genus Daldinia, which is known to produce Nodulisporium-like anamorphs with holoblastic or enteroblastic conidiogenesis. In analyses based on $\beta$-tubulin sequence data, $A$. nemorosum forms a strongly supported clade with Daldinia loculata that is nested within a larger group composed of species producing conidia enteroblastically from annellides, rather than holoblastically in sympodial succession from cylindric conidiogenous cells. This is consistent with the findings of Hsieh et al. (2005), who suggest that enteroblastic conidiogenesis is phylogenetically meaningful in Daldinia. Given the close phylogenetic relationship and morphological similarity among the anamorphs described for other members of this clade, it is likely that the annellidic, Nodulisporium-like anamorphs of species like $D$. decipiens, $D$. petriniae, and $D$. singularis can also be accommodated in the genus Annellosporium.

Phylogenetic analyses of the ITS region reveal a close relationship between $A$. nemorosum and $D$. loculata, with the ex-type strain of $A$. nemorosum nesting within a strongly supported clade representing European and Russian specimens of $D$. loculata. This close association suggests the teleomorph of $A$. nemorosum would likely be consistent with $D$. loculata. However, the anamorph of $D$. loculata has previously been described from European and Russian collections as producing conidiophores with a Nodulisporium-like branching pattern where each terminal branch bears 1-2 sympodially proliferating, holoblastic conidiogenous cells (Petrini
\& Müller 1986, Stadler et al. 2001) in contrast to the percurrently proliferating, enteroblastic conidiogenous cells of $A$. nemorosum. In addition, the conidia of the anamorph of $D$. loculata are reported to be larger than those of $A$. nemorosum $(6-7.5 \times 4.5-5$ vs $4.5-7 \times 2.5-4 \mu \mathrm{m})($ Stadler et al. 2001). This suggests that $A$. nemorosum may be a synanamorph of the Nodulisporium anamorph of $D$. loculata. However, the description of five new species of Daldinia, all bearing strong resemblance to and the common species $D$. eschscholzii and D. concentrica (Stadler et al. 2004) and the description of $D$. petriniae, a species distinguished by its enteroblastic anamorph, from specimens previously accommodated within D. loculata / D. occidentalis Child (Ju et al. 1997) demonstrate that cryptic species can occur within Daldinia. As such, the description of a new anamorphic species with phylogenetic affinities to $D$. loculata suggests that $D$. loculata occurring in North America should be examined more closely to determine if it is indeed a single species producing synanamorphs, or is actually a species complex.

The Daldinia lineage provides a unique opportunity for the study of conidiogenesis in fungi. Pleomorphism occurs in the anamorphs of the genus, as evidenced by the occurrence of both holoblastic and enteroblastic conidiogenesis within single strains of the anamorphs of the species $D$. decipiens, $D$. palmensis, and $D$. petriniae (Ju et al. 1997; Stadler et al. 2001, 2004). The presence of other related species with anamorphs exhibiting strictly enteroblastic conidiogenesis (D. singularis, D. barkalovii, D. govorovae) (Ju et al. 1999, Vasilyeva \& Stadler 2008) and strictly holoblastic conidiogenesis ( $D$. concentrica, D. eschscholzii etc.) (Ju et al. 1999), in addition to the D. loculata / A nemorosum lineage with strains exhibiting either holoblastic or enteroblastic conidiogenesis, provides a phylogenetic framework that could be useful in future comparative genetic studies on the mechanisms controlling conidiogenesis and the evolution of conidiogenesis types within the Daldinia lineage.

Although there is an ongoing debate as to the relevance and utility of dual nomenclature in fungi (Seifert \& Samuels 2000, Gams et al. 2003), we feel the naming of this mitosporic species is warranted. Annellosporium nemorosum was isolated from soil samples taken from a swift fox enclosure at a zoo, where it occurred 
in the absence of a teleomorphic state, and due to its enteroblastic conidiogenesis, it was not immediately morphologically recognizeable as a Nodulisporium-like anamorph of a xylariaceous fungus. Given the free-living state of this fungus, the lack of a succinct way to accommodate it within the existing anamorphic nomenclature for the Daldinia lineage, and that it is both morphologically and phylogenetically distinct from other closely related anamorphs, we feel erecting Annellosporium nemorosum gen. et sp. nov. is not only necessary, but will also provide a nomenclatural framework for unambiguous reference to other Daldinia anamorphs exhibiting enteroblastic conidiogenesis.

Acknowledgements: The author thanks Dr. L. Ryvarden for providing the Latin diagnosis, and George Braybrook for his technical assistance in generating scanning electron micrographs. This work was supported by a Natural Sciences and Engineering Research Council of Canada (NSERC) Canadian Graduate Scholarship (CGS) (master's level), a NSERC-CGS (doctoral level), an Alberta Ingenuity Fund (AIF) Incentive Award, and an Alberta Conservation Association (ACA) Grant in Biodiversity to M.L.D.

\section{References}

Castresana, J. 2000: Selection of conserved blocks from multiple alignments for their use in phylogenetic analysis. - Molecular Biology and Evolution 17: 540-552.

Felsenstein, J. 1985: Confidence limits on phylogenies: an approach to using the bootstrap. - Evolution 39: 783-791.

Gams, W., Korf, R.P., Pitt, J.I., Hawksworth, D.L., Berbee, M.L., Kirk, P.M. \& Seifert, K.A. 2003: Has duel nomenclature for fungi run its course? The article 59 debate. - Mycotaxon 88: 493-508.

Guindon, S. \& Gascuel, O. 2003: A simple, fast, and accurate algorithm to estimate large phylogenies by maximum likelihood. - Systematic Biology 52: 696-704

Hsieh, H.-M., Ju, Y.-M. \& Rogers, J.D. 2005: Molecular phylogeny of Hypoxylon and closely related genera. Mycologia 97: 844-865.

Ju, Y-M., \& Rogers, J.D. 1996: A revision of the genus Hypoxylon. - APS Press: St. Paul, Minnesota.

Ju, Y-M., Rogers, J.D. \& San Martin, F. 1997: A revision of the genus Daldinia. - Mycotaxon 61: 243-293.

Ju, Y.-M., Vasilyeva, L., \& Rogers, J.D. 1999: Daldinia singularis sp. nov. from Eastern Russia and notes on some other taxa. - Mycotaxon 71: 405-412.
Katoh, K. \& Toh, H. 2008: Recent developments in the MAFFT multiple sequence alignment program. Briefings in Bioinformatics 9: 286-298.

O’Donnell, K. \& Cigelnik, E. 1997: Two divergent intragenomic rDNA ITS2 types within a monophyletic lineage of the fungus Fusarium are nonorthologous. - Molecular Phylogenetics and Evolution 7:103-116.

Petrini, L.E. \& Müller, E. 1986: Teleomorphs and anamorphs of European species of Hypoxylon (Xylariaceae, Sphaeriales) and allied genera. - Mycologica Helvetica 1: 501-627.

Posada, D. 2008: jModelTest: Phylogenetic Model Averaging. - Molecular Biology and Evolution 25: 1253 1256 .

Ronquist, F., \& Huelsenbeck, J.P. 2003: MrBayes 3: Bayesian phylogenetic inference under mixed models. - Bioinformatics 19: 1572-1574.

Seifert, K.A. \& Samuels, G.J. 2000: How should we look at anamorphs? - Studies in Mycology 45: 5-18.

Stadler, M., Baumgartner, M. \& Wollweber, H. 2001: Daldinia decipiens sp. nov. and notes on some other European Daldinia spp. inhabiting Betulaceae. - Mycotaxon 80: 167-177.

Stadler, M., Wollweber, H., Jager, W., Briegert, M., Venturella, G., Castro, J.M. \& Tichy, H.V. 2004: Cryptic species related to Daldinia concentrica and D. eschscholzii, with notes on D. bakeri. - Mycological Research 108: 257-273.

Swofford, D.L. 2003. PAUP*: phylogenetic analysis using parsimony (*and other methods). Version 4. Sinnauer Associates, USA.

Tang, A.M.C., Jeewon,R. \& Hyde, K.D. 2009: A re-evaluation of the evolutionary relationships within the Xylariaceae based on ribosomal and protein-coding gene sequences. - Fungal Diversity 34: 127-155.

Triebel, D. Peršoh, D., Wollweber, H. \& Stadler, M. 2005: Phylogenetic relationships among Daldinia, Entonaema, and Hypoxylon as inferred from ITS nrDNA analyses of Xylariales. - Nova Hedwigia 80: 25-43.

Vasilyeva, L. \& Stadler, M. 2008: Pyrenomycetes of the Russian Far East 3. Three new Daldinia species (Xylariaceae). - Mycotaxon 104: 287-296.

Vilgalys, R. \& Hester, M. 1990: Rapid genetic identification and mapping of enzymatically amplified ribosomal DNA from several Cryptococcus species. - Journal of Bacteriology 172: 4238-4246.

Warcup, J.H. 1950: The soil-plate method for isolation of fungi from soil. - Letters to Nature 166: 117-118.

White, T.J., Bruns, T., Lee, S. \& Taylor, J. 1990: Amplification and direct sequencing of fungal ribosomal RNA genes for phylogenetics. - In: Michael, A.J., Gelfand, D.H., Sninsky, J.J. \& White, T.J. (eds), PCR protocols: a guide to the methods and applications, 315-322. Academic Press, New York.

Zhang, N., Castlebury, L.A., Miller, A.N., Huhndorf, S.M., Schoch, C.L., Seifert, K.A., Rossman, A.Y., Rogers, J.D., Kohlmeyer, J., Volkmann-Kohlmeyer, B. \& Sung, G.-H. 2006: An overview of the systematics of the Sordariomycetes based on a four-gene phylogeny. - Mycologia 98: 1076-1087.

Zwickl, D.J. 2006: Genetic algorithm approaches for the phylogenetic analysis of large biological sequence datasets under the maximum likelihood criterion. Ph.D. dissertation, The University of Texas at Austin. 